\title{
Economía, valores y democracia. Diálogo con Christian Felber
}

\author{
Economics, values and democracy. A dialogue \\ with Christian Felber
}

VICENTE ORDOÑEZ ROIG

UNIVERSITAT JAUME I

Entrevista recibida: 23 septiembre 2013

Solicitud de revisión: 01 octubre 2013

Artículo aceptado: 27 octubre 2013

Christian Felber, profesor de Economía de la Universidad de Viena, fundador del movimiento ATTAC y precursor del proyecto Banco Democrático, es uno de los mayores impulsores de la Gemeinwobl-Ökonomie o economía del bien común, un programa de reforma del mercado que tiene por objetivo la creación de un marco legal vinculante en el que los valores empresariales no estén basados en la competitividad y el afán de lucro, sino en la cooperación, redistribución de recursos, solidaridad o respeto medioambiental. Con motivo de su reciente visita a España, tuvimos ocasión de conversar con él sobre algunos aspectos centrales de su obra.

Recerca: En su obra La economía del bien común (2012) hace referencia a la importancia de los valores entendidos a la manera clásica; esto es, como brújula, como guía de la acción humana. Ya Aristóteles (Política 1282b) explica que el fin, no sólo de la política, sino de todas las ciencias y artes es un valor -lo justo-, y a esto lo llama to koiné symphéron; esto es: lo justo es un beneficio compartido por todos, lo justo es un bien porque es de interés común. Parece que este es su punto partida. Si esto es así, ¿quién debe estar al cuidado de los valores que conducen al bien común, quién debe encargarse de educar en esa dirección?

Christian Felber: Sí, el análisis histórico es correcto. Como politólogo, le diré que estos valores surgen de la convivencia. Y el proyecto de una convivencia pacífica y armónica se desarrolla y articula en la constitución. En las distintas constituciones deben figurar, primero, los valores; 
en segundo lugar, los objetivos que se derivan de los valores en los diversos ámbitos políticos, por ejemplo, en cuestiones de política económica; y, por supuesto, los derechos fundamentales, que a su vez se derivan de los valores. Los tres elementos ya existen y están presentes en las constituciones. Todos tenemos los mismos derechos y las mismas libertades por mor de la dignidad humana. La dignidad nos adscribe el mismo valor a todos, es una concepción de igualdad muy propia. Por tanto, tenemos los mismos derechos fundamentales y libertades plasmados en las constituciones. Es el desarrollo íntegro de la constitución lo que debe garantizar la puesta en marcha de los valores.

Recerca: En el mismo libro explica que, más que la eficacia, lo que íntimamente mantiene unida a la sociedad es la confianza. Según la última encuesta del cis (estudio n ${ }^{\circ} 2993$ - barómetro de julio), lo que más preocupa a los españoles después del paro es la «corrupción política y el fraude». ¿Cómo conciliar confianza y política? Porque parece que vivimos en una sociedad con muy mala calidad de vida.

Christian Felber: Creo que confianza y política se pueden ajustar atendiendo a la libertad y a la responsabilidad. Habría que añadir que la libertad y la responsabilidad son dos caras de una misma moneda. Pensemos en lo que ocurre con los mercados. En una economía de mercado realmente libre, responsabilidad y libertad son dos tramos de un mismo camino. Tenemos derecho a la iniciativa individual, empresarial, económica, etc., a condición de que cumplamos ciertos requisitos que nos exige la sociedad: tributar, cumplir con ciertas reglas de regulación, conservar el medio ambiente, repartir de forma justa y equitativa los ingresos, etc. Si una empresa fracasa, el empresario tiene que asumir no sólo los costes, también los daños. Hoy, no solamente se está incumpliendo la primera parte, sino la segunda: las empresas fracasan, pero los daños no los asumen los empresarios, ni los bancos sistémicos. Si uno analiza el capital privado acumulado de los bancos sistémicos, entiende que se podrían pagar los daños una y cien veces. Hasta hace ciento cincuenta años esto era así. Y lo era porque no había una responsabilidad limitada. Hoy la responsabilidad de los accionistas se limita a su participación, a su acción. Antes, si la empresa fracasaba y el daño provocado era mayor que la suma total del valor de las acciones, los accionistas debían hacer frente a las deudas desde su patrimonio, más allá de su participación. Por tanto, esto sería reconciliar libertad y responsabilidad 
en los mercados. En la política, que es todavía más fundamental, tenemos la situación siguiente: la máxima instancia democrática es el pueblo soberano. Paradójicamente, hoy en día el pueblo no tiene ningún poder. Lo único que puede hacer es votar cada cuatro años. Desde luego, votar forma parte de la democracia. Pero la democracia entendida desde esta perspectiva tan limitada no está funcionando, está sufriendo de una insuficiencia múltiple y casi total. Por tanto, hay que repensar cómo construimos las reglas del juego democrático, para que la libertad y la responsabilidad sean reconciliadas. Mi propuesta es volver a pensar un principio que nadie cuestiona: el principio de la división de poderes. Todos están de acuerdo en dividir el poder para que no haya en ningún lugar una sobre-concentración de poder -principalmente los teóricos liberales están de acuerdo en este punto. Las reglas del juego democrático deben ser escritas por el pueblo soberano y los representantes deben limitarse a cumplirlas.Y ya en este primer paso estamos fracasando totalmente. En España, pero también en Austria, Alemania, etc., las constituciones las han escrito los representantes del pueblo auto-adjudicándose el poder, dejando al margen al pueblo soberano. El pueblo soberano no puede realizar enmiendas, no puede corregir la constitución. Simplemente no tiene ese derecho. He pensado cuáles podrían ser los derechos fundamentales y colectivos del pueblo soberano. Éstos serían: definir un gobierno concreto, revocar o corregir al parlamento y cambiar la constitución.

Recerca: ¿Cómo se podría corregir al Parlamento?

Christian Felber: Bueno, me parece que al parlamento se le puede corregir siempre que trate un tema que también interesa al pueblo. Por ejemplo: ¿se debe o no salvar a los bancos sistémicos con el dinero de los contribuyentes? Este tema parece no interesar al parlamento. Pero en democracia no se trata de qué es lo que le interesa al parlamento, sino al pueblo soberano. Y si el pueblo quiere limitar las desigualdades y al parlamento esto le aburre, el pueblo tiene que tener el derecho de poner este tema sobre la mesa y tomar decisiones. Si es necesario celebrar un referéndum, debe realizarse, tal y como ocurrirá en noviembre de 2013 en Suiza. Una consecuencia lógica de esto mismo sería el tercer punto antes mencionado: la posibilidad de cambiar la constitución. En España, en Austria, en la Unión Europea en general, el derecho a cambiar la constitución lo tiene el parlamento. Creo que es una violación abso- 
luta del principio de la división de poderes, porque este derecho tiene que residir en el pueblo soberano. Considero, por ello, que no vivimos en una post-democracia, sino en una pre-democracia. Sigo el análisis que realiza Colin Crouch, aunque cambio un poco los términos. Creo, no obstante, que vamos a ser testigos del estreno de una democracia real en las próximas décadas.

Recerca: Es usted coautor del libro Financial Crimes. Wie Bankenfunktionieren, spekulieren und welche Alternativennötigsind (2011). En él hablan ustedes de lo que consideran las verdaderas causas de la crisis económica -causas que apuntan hacia una redistribución cada vez más desigual de la riqueza, un creciente déficit democrático y un modelo económico insostenible.Al hilo de sus reflexiones, nos gustaría preguntarle por la relación de dependencia que existe entre las instituciones públicas y las instituciones financieras. ¿Cómo regular, controlar o supervisar a aquel de quien depende tu subsistencia?

Christian Felber: Es un problema muy importante, desde luego. Piense usted que en las democracias actuales -y no podemos hablar de democracias reales, como le he dicho antes-, el poder financiero compra y se apodera de la política. No es necesario hablar de la corrupción en España, ni del sistema de financiación política de los Estados Unidos de América -son muchas las evidencias de cómo se puede comprar a un senador o a un diputado. Quizá el caso más obvio es el caso de Austria: un multimillonario, después de haber adquirido un club de fútbol, compra una facción del parlamento. ¿Cómo? Bien, funda un partido y seduce al electorado. Que el parlamento se convierta en una mercancía supone el final de la democracia. Por eso, en mi visión del mundo se necesitan varias medidas. Una sería impedir que hayan desigualdades desmesuradas: que se impida que alguien pueda comprar una emisora televisiva o hacerse con un club en el parlamento. Otra, que en economía no recompensemos el egoísmo -esta ética del egoísmo empresarial se contagia a todos los ámbitos de la experiencia humana y, especialmente, a la política.También propongo que se introduzcan una serie de reformas en el sistema democrático: por ejemplo, prohibir la financiación de los partidos políticos a través de empresas privadas. Son medidas pequeñas, ciertamente, pero necesarias. En cualquier caso, estoy pensando en un modelo democrático que no está basado en la competitividad sino en la cooperación. 
Recerca: Nos parece muy importante algo que también señala en otro de sus libros, 50 VorschlägefüreinegerechtereWelt. GegenKonzernmachtundKapitalismus (2006), donde se refiere a la GlobaleSteuergerechtigkeit, a la justicia fiscal global, y analiza cómo los tipos impositivos medios se han reducido progresivamente sobre los beneficios empresariales. Estudia el caso de Austria, pero en España tenemos una situación parecida, agravada por la amnistía fiscal impulsada desde el Ministerio de Hacienda -difícilmente justificable en términos político-económicos, imperdonable en términos éticos. ¿Qué hacer ante esta situación? Parece complicado subvertir el estado actual de las cosas.

Christian Felber: Tengo mis dudas. Es difícil, sí, pero si hablamos en términos de implementación, no es complicado. Si el pueblo pudiera decidir sobre estos temas veríamos que las soluciones son bastante sencillas. ¿Pero qué ocurre? Que las élites se representan a sí mismas y ofrecen amnistías fiscales a los criminales fiscales, como de hecho sucede en Austria, Alemania, España y otros tantos países. Para mí, el caso de la competencia fiscal y la huida fiscal a través de la libre circulación de capitales a paraísos fiscales es un caso muy sencillo de explicar, análogo al de la amistad. Si tú y yo nos acabamos de conocer, a lo mejor todavía no te doy la llave de mi vivienda o mi tarjeta de crédito. Pero si nos conocemos desde hace muchos años y tú has ganado mi confianza, entonces te doy la llave de mi vivienda, mi tarjeta, etc. Lo mismo sucede entre los Estados. Si otro país ha ganado la confianza de la Unión Europea en términos de cooperación fiscal y da una información automática de las riquezas y los ingresos sobre las riquezas de los residentes europeos y si regula, en segundo lugar, sus mercados financieros de forma estricta -como debería hacer la Unión Europea, aunque de hecho no lo hace-, sólo entonces podría permitirse la libre circulación de capitales. Mientras no sea el caso, todavía no hay confianza y, por eso, tampoco debería haber libre circulación de capitales. El planteamiento es muy sencillo, pero lo que hace falta es que haya una democracia real dentro de la Unión Europea. Dentro de la Unión Europea, no tenemos una regulación estricta de los mercados financieros, no tenemos una justicia fiscal: lo que tenemos es una cantidad importante de criminales fiscales disfrutando de una impunidad total. Por tanto, hasta que no tengamos una democracia interna, no vamos a tener un mercado al servicio de las personas y no podremos entrar en relaciones comerciales justas con otros países. 
Recerca: A esto mismo se refiere en NeueWertefür die Wirtschaft. Eine Alternative zu Kommunismu sund Kapitalismus (2008). En esta obra sostiene que hay una preeminencia de la libertad económica -flujo constante y continuo de capitales, libre circulación de mercancías, deslocalización, etc.- sobre otros valores y libertades -sanidad, derecho a una vivienda digna, etc.-. Déjenos preguntarle por el sistema de pensiones. ¿Cree usted que es en el terreno de las pensiones donde se va a librar la gran batalla macroeconómica de los próximos años?

Christian Felber: Sí, es un campo de batalla: otro sacrificio en el altar de la globalización. Para mí, las libertades económicas son libertades secundarias: la clave está en los derechos fundamentales. Esto es importante porque hay otros pensadores -por ejemplo, el supuestamente liberal Hayek-, que vienen a decir que las libertades económicas son la precondición para prácticamente todas las demás libertades. Esto, para mí, es la inversión antiliberal de las cosas. Porque los derechos fundamentales y políticos son más importantes. Un ejemplo muy sencillo: yo no puedo matarle, descuartizarle y vender su carne como alimento para perros. No lo puedo hacer porque su derecho fundamental a la vida y a la integridad vale más que mi libertad económica. Esto es importantísimo. Hay una jerarquía muy clara entre derechos fundamentales y libertades económicas. Pero la globalización, hoy, tanto a nivel internacional como europeo, actúa al revés. Se han desarrollado las libertades económicas -libre comercio, libre flujo de capitales, libertad de inversión transfronteriza y protección de la propiedad, tanto física como intelectual-, sin tener una legislación obligatoria para respetar los derechos humanos a través de las empresas; sin tener una legislación vinculante en cuanto a las normas laborales; sin poder asegurar el sistema de pensiones; sin tener una legislación medioambiental vinculante; sin armonizar medidas fiscales de transparencia, anticorrupción, etc. Este es el estado inverso de las cosas y el estado antiliberal. Todos nos hablan del mercado liberal, de que los liberales se han salido con la suya, etc., pero esto no es nada liberal. Nosotros proponemos un proyecto completamente liberal. Y ello quiere decir que debe haber una preeminencia de los derechos fundamentales, de los derechos humanos. Considero que es en este contexto donde hay que situar la discusión sobre las pensiones. Solamente cuando estén aseguradas las pensiones, sólo entonces podremos entrar en un comercio transfronterizo. Y sólo aquellas empresas que cumplan con estos requisitos tendrán acceso al mercado internacional.Así de simple. 
Recerca: Le queríamos hacer una pregunta doble: en los apuntes a la Dialéctica de la Ilustración, Max Horkheimer afirma que «no es posible deshacerse del terror y conservar la civilización». ¿Cree usted que lo contrario es posible? Esto es: ¿cree usted que es posible deshacerse de las injusticias, de la miseria y el terror y conservar la civilización? La segunda cuestión tiene que ver con la posible utilización de sus teorías por parte de corporaciones, empresas de dudoso pedigrí democrático, etc. ¿Podrían desviar la teoría del bien común de su origen?

Christian Felber: ¿Cómo lo van a hacer? Gandhi dijo: primero te ignoran, luego se ríen de ti, después luchan contra ti y, finalmente, ganas tú. Mi confianza se cifra en lo siguiente: ganaremos todos aquellos que queramos una democracia sin fisuras, democracia que será fruto de un proceso en el que habremos definido colectivamente qué entendemos por bien común, qué cuentas deben rendir las empresas y cómo medimos el éxito de la economía nacional. La historia muestra que, a la larga, las autoridades naturales se salen con la suya, mientras que las autoridades basadas en la violencia, en el poder jerárquico, no perduran -desde el Imperio Romano hasta los nazis, pasando por el apartheid: han sido sistemas poderosísimos. Estos sistemas totalitarios tienen algo en común: han desaparecido todos. ¿Por qué? Porque no eran autoridades naturales. Su autoridad estaba basada en el poder jerárquico y en la violencia. No sé cuándo será, pero tarde o temprano tendremos una economía del bien común democrática.

Recerca: Zygmunt Bauman comentaba el año pasado, en este mismo foro, que uno de los mayores problemas con el que nos enfrentamos tiene que ver con lo siguiente: el mercado se ha globalizado, pero las instituciones siguen enmarcadas en el esquema del estado-nación; esto es: actúan desde una perspectiva local. ¿Cree que es así? ¿Cómo podría cambiar esta situación asimétrica?

Christian Felber: Creo que sí o, al menos, es una parte del problema. Primero deberíamos definir el objetivo y con ello el grado de globalización. Mi intuición económica y política me dice que el mercado mundial debería ser la sal en la sopa, pero la sopa debería ser local o regional, de forma que tuviéramos el mayor grado de autoabastecimiento posible, por cuestiones de autonomía, responsabilidad, resiliencia, sostenibilidad ecológica, etc. Son muchas razones de peso. Yo abogo por una mezcla 
sensata de lo local y lo internacional. De este modo construiremos el comercio internacional. Porque el libre comercio no es ningún fin en sí mismo: es una herramienta que va en la línea de los objetivos más importantes de esta democracia, objetivos que culminarían en la sostenibilidad ecológica. El libre comercio, por tanto, es una herramienta entre muchas. Creo que en este punto hace falta una regulación a nivel global. Es decir: hace falta una autoridad fiscal mundial que proteja los derechos fundamentales -no sólo los derechos humanos, también los derechos laborales, por ejemplo, de suerte que esa autoridad mundial pueda sancionar a las empresas transnacionales. Por tanto, no es suficiente con una justicia nacional, debe haber una justicia internacional porque los derechos y las libertades están internacionalizados. Esto es tan lógico que las empresas no sólo lo han entendido, sino que ya lo han puesto en práctica. La asimetría jurídica que existe a favor de las empresas es un disparate. Si una empresa ve violada sus libertades económicas, puede recurrir a un tribunal global. Por ejemplo, un tribunal adherido al Banco Mundial que regule los conflictos sobre las inversiones. Sin ir más lejos, Philip Morris está pidiendo a Uruguay dos mil millones de dólares, porque existen en este país ciertas limitaciones para vender su tabaco. Hay otra sentencia dictada contra Ecuador. En este caso, una multinacional petrolera que se considera perjudicada y reclama libertad para invertir, explotar tierras, etc. Por tanto, ya existen los tribunales a nivel internacional para las libertades económicas de las empresas. Por supuesto que hay que defender y proteger a las empresas, pero esto es menos importante que proteger los derechos humanos, los derechos laborales, la seguridad social y los derechos de la naturaleza. Una vez que hayamos establecido los correspondientes organismos, tribunales y autoridades para estos objetivos políticos tan importantes, podemos hablar del respeto y la protección jurídica a las empresas.

Recerca: Acaba de mencionar la necesidad que tenemos de una autoridad global. Sin embargo, ni siquiera hemos sido capaces de implantar una fiscalidad común a nivel europeo. Esto es nuevamente problemático.

Christian Felber: Ya he hablado de la perfecta analogía y del fracaso liberal y democrático de la construcción de la clase europea y el mercado mundial. Hemos establecido un mercado sin fiscalización comunitaria, sin criterios de convergencia ecológica y social, sin normativas laborales dentro del mercado común europeo, etc. Este constructo político no 
tiene interés alguno en desarrollar reglas vinculantes para el mercado mundial. Por eso volvemos siempre a lo mismo: primero hay que establecer una democracia real en los países nacionales; después, construir una casa europea democrática, que ponga en su lugar los derechos fundamentales y las libertades económicas. Sólo así este constructo político tendrá otra perspectiva, otro cariz democrático.

\section{BIBLIOGRAFÍA}

Felber, Christian (2006): 50 Vorschlägefüreinegerechtere Welt. GegenKonzernmacht und Kapitalismus, Viena, ZsolnayVerlag.

- (2006): Das kritische EU-Buch - Warumwireinanderes Europa brauchen, Viena, Deuticke.

- (2008): NeueWertefür die Wirtschaft - Eine Alternative zuKommunismus und Kapitalismus, Viena, ZsolnayVerlag.

- (2009): KooperationstattKonkurrenz - 10 Schritteaus der Krise, Viena, ZsolnayVerlag.

- (2011): Financial Crimes. Wie Banken funktionieren, spekulieren und welche Alternativen nötigsind, Hamburgo, VSA Verlag.

- (2012): La economía del bien común, Barcelona, Deusto.

- (2013): Salvemos el Euro, Madrid, Anaya Multimedia. 